\title{
Obesity-Related Hypertension in Children
}

\author{
Tammy M. Brady* \\ Division of Pediatric Nephrology, Johns Hopkins University School of Medicine, Baltimore, MD, United States
}

Obesity and hypertension have both been on the rise in children. Each is associated with increased cardiovascular disease risk and both track into adulthood, increasing the prevalence of heart disease and related morbidity and mortality. All children should be screened for hypertension, but children with comorbid obesity may not only particularly benefit from the screening but may also prove the most challenging to screen. Increased arm circumference and conical arm shape are particularly problematic when attempting to obtain an accurate blood pressure (BP) measurement. This review focuses on the unique aspects of hypertension evaluation and management in the child with comorbid obesity. Specific traditional and non-traditional risk factors that may contribute to elevated BP in children with obesity are highlighted. Current proposed pathophysiologic mechanisms by which obesity may contribute to elevated BP and hypertension is reviewed, with focus on the role of the sympathetic nervous system

OPEN ACCESS

Edited by:

Miriam Schmidts,

Radboud University Nijmegen,

Netherlands

Reviewed by:

Juan C. Kupferman,

Maimonides Medical Center,

United States

Aftab S. Chishti,

University of Kentucky,

United States

*Correspondence:

Tammy M. Brady

tbrady8@jhmi.edu

Specialty section:

This article was submitted

to Pediatric Nephrology,

a section of the journal

Frontiers in Pediatrics

Received: 14 June 2017

Accepted: 28 August 2017

Published: 25 September 2017

Citation:

Brady TM (2017) Obesity-Related

Hypertension in Children.

Front. Pediatr. 5:197.

doi: 10.3389/fped.2017.00197 and the renin-angiotensin-aldosterone system. This review also presents a targeted treatment approach to children with obesity-related hypertension, providing evidence for the recommended therapeutic lifestyle change that should form the basis of any antihypertensive treatment plan in this population of at-risk children. Advantages of specific pharmacologic agents in the treatment of obesity-related hypertension are also reviewed.

Keywords: pediatrics, blood pressure, cardiovascular disease, adiposity, adipocyte, adipose tissue dysfunction

\section{INTRODUCTION}

Since 1980, the prevalence of obesity among children and adolescents has almost tripled. Current estimates suggest that approximately $17 \%$ of children 2-19 years of age are obese. This percentage equates to 12.7 million children in the United States (1). These data are more striking when you include those who are overweight: $30 \%$, or 25 million, US children are overweight/obese.

While these statistics are remarkable in their own right, the implications are particularly concerning. Children with obesity are at a significantly increased risk for cardiovascular disease (CVD): they have higher systolic and diastolic blood pressure (BP) and greater evidence of dyslipidemia and insulin resistance (2). In fact, $70 \%$ of obese children have at least one CVD risk factor, and $39 \%$ have two or more (3). These CVD risk factors, along with obesity, are not only associated with heart disease in childhood (i.e., atherosclerosis and left ventricular hypertrophy) but are associated with an increased prevalence of CVD risk factors in adulthood-which results in increased CVD morbidity and mortality (4-8).

Abbreviations: AAP, American Academy of Pediatrics; ACEi, angiotensin converting enzyme inhibitor; ARB, angiotensin receptor blocker; BMI, body mass index; BP, blood pressure; CI, confidence interval; CVD, cardiovascular disease; DASH, dietary approaches to stop hypertension; NHANES, National Health and Nutrition Examination Survey; RAAS, renin-angiotensin-aldosterone system; SNS, sympathetic nervous system. 
These known associations and the now well recognized phenomenon of CVD risk factor tracking from childhood into adulthood has resulted in a greater emphasis on obesity prevention. In addition, the American Heart Association and the American Academy of Pediatrics (AAP) have emphasized the importance of primordial and primary prevention to achieve CVD risk reduction in youth $(9,10)$. An essential component of this strategy is regular screening for elevated BP and hypertension among children. Current guidelines recommend at least yearly BP measurements in all children 3 years of age and above. Any BP elevation should be confirmed with repeated measurements and the diagnosis of hypertension should be given to any child with a sustained elevation in his/her BP at or above the 95th percentile when measured by manual auscultation. All children with a diagnosis of hypertension should undergo evaluation for a secondary cause (11).

\section{EVALUATION OF THE CHILD WITH OBESITY AND HYPERTENSION}

As introduced above, children with elevated BP should have their BP elevations confirmed with repeated measurements done by manual auscultation. Children with obesity can present unique challenges to BP measurement. For one, their arm size may be sufficiently large to require a BP cuff much bigger than would be expected by the labeling on the cuff (i.e., adult, large adult, thigh). Analyses using National Health and Nutrition Examination Survey (NHANES) data revealed that, based on measured mid-arm circumferences, some children as young as $3-5$ years of age require an adult cuff, and starting at age 12 years some children require the use of a thigh cuff for proper BP measurement (12). Individuals with obesity also often have conically shaped arms, with a large circumference proximally that tapers to a much smaller circumference at the cubital fossa. The difference between the proximal and distal upper arm circumferences can be as large as $20 \mathrm{~cm}$, with the average difference being $8.7 \mathrm{~cm}$ (13). Finally, while the mid-arm circumference of children with obesity is often larger than might be expected for age, their arm length is not different than would be expected. This leads to an arm length that is disproportionally short for the cuff required for the measured arm circumference. Often the appropriately sized cuff will overlay the cubital fossa, making BP measurement by manual auscultation difficult and raising the possibility of inaccurate measurements.

These challenges are particularly problematic because accurate $\mathrm{BP}$ measurement in the child with obesity is perhaps even more important than among those peers of normal or healthy weight. In children up to 20 years of age, obesity is defined as a body mass index (BMI) $\geq 95$ th age- and sex-specific percentile and overweight is defined as a BMI $\geq 85$ th percentile but $<95$ th percentile. Severe obesity in children is defined as either a BMI $\geq 120 \%$ of the 95 th percentile (corresponding to the 99th percentile $\mathrm{BMI}$ ), or a $\mathrm{BMI} \geq 35 \mathrm{~kg} / \mathrm{m}^{2}$ (corresponding to the cutpoint of Class II obesity in adults), whichever is lower. After age 20 years, adult cutpoints for overweight and obesity apply (BMI between 25 and $30 \mathrm{~kg} / \mathrm{m}^{2}$ and BMI $\geq 30 \mathrm{~kg} / \mathrm{m}^{2}$, respectively). Adult studies have demonstrated that the risk of hypertension increases substantially with increasing BMI, with the odds of hypertension as great as 4.8 among adults with Class III obesity (BMI $\geq 40 \mathrm{~kg} / \mathrm{m}^{2}$ ) when compared to adults with a normal BMI (14). Obesity is also associated with resistant hypertension: hypertensive adults with Class III obesity had a $30 \%$ lower odds [OR 0.7, 95\% confidence interval (CI) 0.5-0.9] of achieving a BP $<140 / 90$ compared to those with a normal BMI (15).

Once a child with obesity has confirmed hypertension, he/she should undergo an evaluation to investigate for secondary causes of hypertension and screen for CVD risk factors. This evaluation should include the following (11):

\begin{tabular}{ll}
\hline Evaluation & Unique aspects to obesity \\
\hline Detailed history & Sleep history \\
& $\circ$ Daytime somnolence \\
& $\circ$ Snoring \\
& $\circ$ Witnessed apneic events \\
- & Diet history \\
& $\circ$ Sugar-sweetened beverage intake \\
& $\circ$ Fiber intake \\
& $\circ$ Total calories consumed \\
& $\circ$ Timing and frequency of meals \\
- Physical activity & $\circ$ Amount and intensity \\
& $\circ$ Musculoskeletal pain (which might \\
& impact ability to be active) \\
- Psychosocial history & $\circ$ Depression \\
& $\circ$ Anxiety \\
\hline & Anthropometrics \\
& $\circ$ Body mass index \\
& $\circ$ Waist circumference \\
- Skin exam & $\circ$ Acanthosis nigricans \\
& $\circ$ Hirsutism \\
& $\circ$ Striae \\
- Abdominal exam & $\circ$ Hepatomegaly \\
- Fasting lipids \\
- Fasting glucose and insulin \\
- Hemoglobin A1c \\
Aspartate transaminase and alanine \\
transaminase \\
\hline Detailed physical exam
\end{tabular}

Tests to consider, particularly in children with obesity hypertension:

\begin{tabular}{ll}
\hline Evaluation & Unique aspect to obesity \\
\hline Polysomnography & Obstructive sleep apnea \\
\hline Toxicology screen & $\begin{array}{l}\text { Depression and anxiety are increased in obese } \\
\text { children, leading to increased risk for illicit substances }\end{array}$ \\
\hline
\end{tabular}

If a secondary cause is not determined after the initial evaluation in an older child or a child with a BP close to the 95th percentile, additional evaluation may not be warranted. One may then consider a diagnosis of primary or obesity-related hypertension. 


\section{ROLE OF ADIPOSITY ON BP IN CHILDREN}

As in adults, BMI influences BP in children. In a large cohort study of more than 100,000 children and adolescents followed for several years, those with obesity and severe obesity had higher $\mathrm{BP}$ at baseline and a greater odd of developing hypertension years later than those of lower BMI categories (16). The influence of adiposity on BP in children is also evident in the normative tables utilized by pediatric providers to diagnose hypertension. These tables were developed based on the first manual BP measurement obtained in children enrolled in any of 11 separate studies. The approximately 60,000 healthy children included in this database included children of normal weight as well as those with overweight or obesity. In fact, $21 \%$ of the included children had a BMI in the overweight or obese category. The impact of including these children is significant: when overweight and obese children are excluded from the normative table database, BP norms are lower by several $\mathrm{mmHg}$ across the board (17). The recently updated pediatric hypertension guidelines have addressed this issue by developing new tables based upon data from youth without overweight/obesity (18).

There are several possible pathophysiological pathways to explain why adiposity is associated with elevated BP and hypertension. The central tenet relates to the dysfunctional adipocyte and neurohormonal activation of the sympathetic nervous system (SNS). It is important to remember that the adipocyte not only serves as a storage depot for fat but is also an active endocrinological cell. Overweight and obesity is associated with a greater mass of adipose tissue, which includes adipocytes as well as pre-adipocytes, macrophages, and fibroblasts among other cell types (19). This tissue secretes various hormones and cytokines, known as adipokines, to maintain homeostasis. In the obese state, adipocytes are greater in number and size, and increasing amounts of adipokines are secreted. Over time, there is upregulation of pro-inflammatory adipokines. When the pro-inflammatory adipokines (leptin, resistin and IL-6, as examples) overwhelm the anti-inflammatory (i.e., adiponectin) adipokines, this imbalance leads to adipose tissue dysfunction and a chronic inflammatory state.

Many of these adipokines lead to an increase in SNS activity. Leptin, for example, has been shown to activate the SNS and studies in humans have demonstrated that Leptin deficiency is associated with lower SNS activity. This Leptin-mediated SNS activation appears to be dependent on the expression of leptin receptors on the proopiomelanocortin neurons in the brain (20). Mice without these receptors are resistant to the hypertensive effects of Leptin (21) and rats given alpha and beta blocker medications were similarly resistant to BP effects of intravenous infusion of Leptin (22).

Sympathetic nervous system activation can impact all organs, but in obesity appears to preferentially impact the renal vascular beds. Increasing BMI in humans is associated with increasing amounts of norepinephrine spill over in the kidneys, suggesting a link between obesity-related SNS activation and the neural release of renin (23). So, in addition to its direct vasoconstricting effects, increased SNS activity also leads to elevated BP and hypertension by increasing renin-angiotensin-aldosterone system (RAAS) activity. RAAS activity increases BP directly (angiotenisin II-mediated vasoconstriction and further SNS activation) and indirectly (angiotensin II- and aldosterone-mediated salt and water tubular reabsorption and $\mathrm{ADH}$-mediated water retention). RAAS activity is further increased with increasing fat mass: adipocytes also secrete RAAS hormones and mineralocorticoid stimulating factors, with the relative contribution of these circulating levels related to the amount of adipose tissue present (24).

In the obese state, there is also increased inflammation with macrophages infiltrating the adipose tissue, and there is increased free fatty acid levels. Dyslipidemia, specifically elevated LDL-cholesterol and triglycerides and low HDL-cholesterol, is frequently comorbid with obesity. Elevated cholesterol is a known CVD risk factor, but its contribution to elevated BP and hypertension is complex. In addition to causing atherosclerosis, elevated LDL-cholesterol induces chronic inflammation, activates the SNS (25), and increases RAAS activity $(26,27)$. Among hypercholesterolemic individuals treated with statin therapy, SNS activity decreases along with a decrease in LDLlevels $(28,29)$.

Increased oxidative stress is another significant contributor to obesity-related hypertension. Oxidative stress also promotes SNS activation throughout the hypothalamus. Ultimately, with obesity full metabolic dysfunction occurs, leading to endothelial dysfunction, impaired pressure natriuresis, and poor vascular function, with hypertension the clinically identifiable outcome (30).

The increase in RAAS and SNS activation in obesity-related hypertension is important to recognize, as this has treatment implications for patients with obesity-related hypertension. As mentioned above, the serum levels of almost all components of RAAS are elevated in obesity, and in fact, the amount of adipose tissue present determines the relative amount of circulating angiotensinogen and angiotensin II (24). Weight loss, the first-line treatment for individuals with obesity-related hypertension, leads to a decrease in SNS activity which has direct effects on arterial pressure (decreased peripheral vasoconstriction), indirect effects on arterial pressure (improved pressure natriuresis resulting in lower intravascular volume), and a decrease in renin release from the kidney. In fact, menopausal women who successfully lost $5 \%$ of their body weight decreased their SBP by $7 \mathrm{mmHg}$ and had lower angiotensinogen, renin, aldosterone, and angiotensin converting enzyme levels (31), providing experimental evidence for this effective means of treating obesity-related hypertension.

The important role of the SNS in obesity-related hypertension has been demonstrated in animal and human studies. In an experiment comparing the effect of weight gain on BP between dogs with and without bilateral renal denervation, both groups were fed the same high-fat diet and both had the same weight gain after 5 weeks. Despite this, only the dogs with intact renal innervation had higher BP and diminished urinary sodium excretion (32). In adults, adiposity is directly associated with increased muscle sympathetic nerve activity, which is considered a marker of overall sympathetic outflow (33). And, while invasive studies of SNS activity have not been done in children, children with 
obesity-related hypertension have higher resting heart rates and increased BP variability than non-obese normotensive children (34). Both of these findings are considered indirect markers of SNS activity.

Finally, as with other visceral organs, in the obese state, the kidney can become fat encapsulated (19). When this occurs, there is increased renal interstitial fluid pressure and slower tubular flow rates which ultimately leads to increased sodium reabsorption and increased intravascular volume.

\section{TREATMENT APPROACH TO OBESITY- RELATED HYPERTENSION}

The primary approach to all children with obesity-related hypertension should focus on the attainment of a healthy weight and achievement of a heart healthy lifestyle. The AAP recommends a staged approach to obesity treatment, with weight loss recommended for children 6 years of age and above when BMI is in the obese category and weight maintenance for growing children when BMI is in the overweight category (35). Weight loss is particularly important for children with obesity-related hypertension because it addresses the underlying etiology, it improves comorbidities and it reduces SNS activation, leading to lowering of BP. Several studies conducted in overweight and obese children ranging from 6 to 16 years of age have demonstrated the effectiveness of weight loss on lowering BP in children. These studies all incorporated diet, physical activity, education, and counseling and demonstrated a decrease in SBP from 6 to $16 \mathrm{mmHg}$ over 5- to 12 -month periods of intervention (36-38).

Dietary change is another important aspect of the lifestyle modifications needed to treat obesity-related hypertension. In 2011, the AAP published updated dietary recommendations for the treatment of hypertension (10). Regardless of stage of hypertension or etiology of hypertension, hypertensive children should institute the cardiovascular health integrated lifestyle diet and dietary approaches to stop hypertension (DASH) eating plan, which includes:

- increased intake of fresh vegetables, fruits, and low-fat dairy

- reduced carbohydrate, fat, and processed sugar intake

- limited/avoidance of sugar-sweetened beverages

- encouraged intake of foods with high dietary fiber content (age $+5=$ number of grams/day up to $14 \mathrm{~g} / 1000 \mathrm{kcal}$ )

These dietary interventions have been shown to decrease $\mathrm{BP}$ in adults. In a randomized controlled feeding trial of adults with pre- or stage 1 hypertension, systolic BP was reduced by 6.6 (95\% CI: 4.0-9.1) $\mathrm{mmHg}$ when following a DASH diet with a high sodium intake (compared to a usual diet with high sodium intake) and by 8.3 (95\% CI: 6.6-10.0) $\mathrm{mmHg}$ when following a low-sodium diet in the setting of a Usual diet (compared to a high-sodium Usual diet) among those with hypertension. The degree of $\mathrm{BP}$ reduction was even greater when both interventions were implemented simultaneously: systolic BP was reduced by
11.5 (95\% CI: 8.9-14.1) mmHg when a low sodium, DASH diet was followed (39) Hypertensive adolescents have also demonstrated decreased BP when enrolled in a clinic-based behavioral nutrition intervention emphasizing a DASH-type diet: systolic BP decreased by $10 \mathrm{mmHg}$ and diastolic BP decreased by $6 \mathrm{mmHg}$ among those prescribed a DASH-type diet (40).

Avoidance of sugar-sweetened beverages can also lead to weight loss among children and has been independently associated with BP reduction in adults. Two randomized controlled trials in children, one of overweight/obese children and another of normal-weight children, each demonstrated that elimination of sugar containing beverages leads to a reduction in weight and measures of adiposity $(41,42)$. In the PREMIER: Lifestyle Interventions for $\mathrm{BP}$ Control trial, a reduction of one 12-oz serving of sugar-sweetened beverages/day among adults over 18 months was associated with a reduction of systolic BP by $1.8 \mathrm{mmHg}(95 \%$ CI: 1.2-2.4) and diastolic BP by $1.1 \mathrm{mmHg}$ (95\% CI: 0.7-1.4). These results remained significant even after adjusting for weight change (43).

There are no current guidelines regarding the degree of sodium reduction in children for the treatment of hypertension. Children should adhere to the Dietary Guidelines for Americans 20152020 (44) which states that children $\geq 14$ years should limit daily sodium intake to $<2,300 \mathrm{mg}$ and younger children should limit sodium their sodium intake even more, with the upper tolerable limit for children 1-3 years of age being 1,500 mg. These guidelines also state broadly that pre-hypertensive and hypertensive individuals should reduce sodium intake to $<1,500 \mathrm{mg}$. There is evidence to suggest that these recommendations may have a more significant impact on BP among children and adolescents who are overweight/obese than those who are not. In an NHANES study that included 6,235 children $8-18$ years of age, $37 \%$ of whom were overweight or obese, usual sodium intake was estimated by multiple 24 -h recalls. Notably, overall mean sodium intake was much greater than recommendations, with mean intake $3,387 \mathrm{mg} /$ day. Overall, each $1 \mathrm{~g}$ of sodium intake per day was associated with an increased systolic BP SD score of 0.121 (95\% CI 0.034-0.207) even after adjusting for age, sex, race, and energy intake. However, when the subjects were stratified by weight status, sodium intake was no longer associated with BP among the children of normal weight but it remained significantly associated with BP among the overweight/obese children (each 1 g sodium intake was associated with an increase in systolic BP SDS score of 0.197, 95\% CI 0.036-0.357) (45). This differential effect of adiposity on the association of sodium intake and BP may be explained by the activation of the RAAS and SNS in the obese state as detailed above. Future studies need to explore this further.

Other essential components of the Heart Healthy Lifestyle include regular physical activity and a limit to sedentary activities. Specifically, children $\geq 5$ years of age should partake in at least $1 \mathrm{~h}$ of moderate-to-vigorous exercise every day and all children should decrease their sedentary activities to $<2 \mathrm{~h}$ per day. This may be difficult to achieve for children with obesity due to comorbidities such as arthritis, Blount's disease, slipped capital femoral epiphysis, spinal complications and acute fractures, all of which contribute to decreased mobility. Referral to physical 
therapy can be helpful for some children as they work to achieve their physical fitness goals.

\section{ROLE OF PHARMACOLOGIC THERAPY}

While all children with obesity-related hypertension should be prescribed therapeutic lifestyle changes, some children will also require an antihypertensive medication to adequately treat their hypertension. Children with a secondary etiology of hypertension, who are symptomatic, who have diabetes (type 1 or type 2), or who have end-organ damage such as left ventricular hypertrophy should all be prescribed an antihypertensive medication. In addition, children with persistent hypertension after 6-12 months of instituting a heart healthy lifestyle should also be prescribed a medication to lower their BP while they continue to work on weight loss and lifestyle changes (11).

As with any medication, the particular agent chosen should be aimed at treating the underlying etiology, with particular attention being paid to comorbid conditions. As activation of the RAAS system is one of the main ways in which obesity contributes to elevated BP and hypertension, it follows that angiotensin converting enzyme inhibitors (ACEi) or angiotensin receptor blockers (ARB) would be appropriate initial agents in the treatment of obesity-related hypertension. In addition to being able to directly target pathways leading to elevated BP, ACEi or ARB may also have beneficial effects on diabetes and dyslipidemia, two common comorbidities in overweight and obese individuals (46).

Some agents are less ideal in the treatment of obesityrelated hypertension. Diuretics, for example, may have similar antihypertensive efficacy as ACEi/ARB in hypertensive, obese adults and may be associated with lower CV events in adults, but they also reduce intravascular volume and cardiac output and stimulate the SNS and RAAS. These agents can also worsen insulin resistance and dyslipidemia and can increase glucose and uric acid levels, particularly in obese individuals. Beta-blockers reduce $\mathrm{BP}$ by decreasing both cardiac output and renin activity. However, these agents can lead to weight gain and increased triglycerides and decreased HDL-cholesterol levels. They also have inferior outcomes in adults, particularly when restricted to obese subjects, which may be related to these known side effects $(47,48)$.

\section{REFERENCES}

1. Ogden CL, Carroll MD, Fryar CD, Flegal KM. Prevalence of obesity among adults and youth: United States, 2011-2014. NCHS Data Brief(2015) (219):1-8.

2. Friedemann C, Heneghan C, Mahtani K, Thompson M, Perera R, Ward AM. Cardiovascular disease risk in healthy children and its association with body mass index: systematic review and meta-analysis. BMJ (2012) 345:e4759. doi:10.1136/bmj.e4759

3. Freedman DS, Mei Z, Srinivasan SR, Berenson GS, Dietz WH. Cardiovascular risk factors and excess adiposity among overweight children and adolescents: the Bogalusa Heart Study. J Pediatr (2007) 150:12-7.e2. doi:10.1016/ j.jpeds.2006.08.042

4. Berenson GS, Srinivasan SR, Bao W, Newman WP III, Tracy RE, Wattigney WA. Association between multiple cardiovascular risk factors and atherosclerosis in children and young adults. The Bogalusa Heart Study. N Engl J Med (1998) 338:1650-6. doi:10.1056/NEJM199806043382302
As with non-obesity-related hypertension, the goal of therapy is to lower BP. BP should be treated to below the 90th percentile, or below $130 / 80$ for children $\geq 13$ years old (18).

\section{CONCLUSION}

Obesity-related hypertension is highly prevalent among US children. There are multiple mechanisms by which obesity can lead to elevated $\mathrm{BP}$ and increased CVD risk. Central to this is adipose tissue dysfunction, related to an imbalance in the pro- and antiinflammatory activities of the adipocyte. First-line antihypertensive therapy for children with obesity-related hypertension is weight loss. In addition, instituting a heart healthy lifestyle that includes daily physical activity and a diet rich in fruits and vegetables, fiber and low-fat dairy, that is also low in carbohydrates and sugar-sweetened beverages is essential in the treatment of obesity-related hypertension. There may be challenges to this in children with obesity, related to comorbid conditions such as depression, anxiety, and decreased mobility. A multidisciplinary approach is often required for maximal effectiveness. Some children will require antihypertensive pharmacologic therapy. In children, no agent has been shown to be more effective at lowering BP than another. However, the decreased CV events found among adults treated with RAAS blockers and the adverse metabolic profile associated with beta blocker and diuretic use, make RAAS blockade potentially beneficial in the treatment of pediatric obesity-related hypertension.

\section{AUTHOR CONTRIBUTIONS}

TB was the sole contributor to the structure of the work and to the acquisition and interpretation of data for the work. TB was solely responsible for drafting the work, provided final approval of the version to be published; and agreed to be accountable for all aspects of the work in ensuring that questions related to the accuracy or integrity of any part of the work are appropriately investigated and resolved.

\section{FUNDING}

TB is funded by the NIH/NHLBI (1K23 HL119622-01).

5. Morrison JA, Friedman LA, Gray-McGuire C. Metabolic syndrome in childhood predicts adult cardiovascular disease 25 years later: the Princeton Lipid Research Clinics Follow-up Study. Pediatrics (2007) 120:340-5. doi:10.1542/ peds.2006-1699

6. Strong JP, Malcom GT, McMahan CA, Tracy RE, Newman WP III, Herderick EE, et al. Prevalence and extent of atherosclerosis in adolescents and young adults: implications for prevention from the pathobiological determinants of atherosclerosis in youth study. JAMA (1999) 281:727-35. doi:10.1001/jama.281.8.727

7. Brady TM, Fivush B, Flynn JT, Parekh R. Ability of blood pressure to predict left ventricular hypertrophy in children with primary hypertension. J Pediatr (2008) 152:73-8, 78.e1. doi:10.1016/j.jpeds.2007.05.053

8. Brady TM, Appel LJ, Holmes KW, Fivush B, Miller ER III. Association between adiposity and left ventricular mass in children with hypertension. J Clin Hypertens (Greenwich) (2016) 18:625-33. doi:10.1111/ jch. 12717 
9. Weintraub WS, Daniels SR, Burke LE, Franklin BA, Goff DC Jr, Hayman LL, et al. Value of primordial and primary prevention for cardiovascular disease: a policy statement from the American Heart Association. Circulation (2011) 124:967-90. doi:10.1161/CIR.0b013e3182285a81

10. Expert Panel on Integrated Guidelines for Cardiovascular Health and Risk Reduction in Children and Adolescents; National Heart, Lung, and Blood Institute. Expert panel on integrated guidelines for cardiovascular health and risk reduction in children and adolescents: summary report. Pediatrics (2011) 128(Suppl 5):S213-56. doi:10.1542/peds.2009-2107C

11. National High Blood Pressure Education Program Working Group on High Blood Pressure in Children and Adolescents. The fourth report on the diagnosis, evaluation, and treatment of high blood pressure in children and adolescents. Pediatrics (2004) 114:555-76. doi:10.1542/peds.114.2.S2.555

12. Ostchega Y, Hughes JP, Prineas RJ, Zhang G, Nwankwo T, Chiappa MM. Mid-arm circumference and recommended blood pressure cuffs for children and adolescents aged between 3 and 19 years: data from the National Health and Nutrition Examination Survey, 1999-2010. Blood Press Monit (2014) 19:26-31. doi:10.1097/MBP.0000000000000008

13. Palatini P, Frick GN. Cuff and bladder: overlooked components of BP measurement devices in the modern era? Am J Hypertens (2012) 25:136-8. doi:10.1038/ajh.2011.213

14. Nguyen NT, Magno CP, Lane KT, Hinojosa MW, Lane JS. Association of hypertension, diabetes, dyslipidemia, and metabolic syndrome with obesity: findings from the National Health and Nutrition Examination Survey, 1999 to 2004. J Am Coll Surg (2008) 207:928-34. doi:10.1016/j.jamcollsurg.2008. 08.022

15. Bramlage P, Pittrow D, Wittchen HU, Kirch W, Boehler S, Lehnert H, et al. Hypertension in overweight and obese primary care patients is highly prevalent and poorly controlled. Am J Hypertens (2004) 17:904-10. doi:10.1016/j.amjhyper.2004.05.017

16. Parker ED, Sinaiko AR, Kharbanda EO, Margolis KL, Daley MF, Trower NK, et al. Change in weight status and development of hypertension. Pediatrics (2016) 137:e20151662. doi:10.1542/peds.2015-1662

17. Rosner B, Cook N, Portman R, Daniels S, Falkner B. Determination of blood pressure percentiles in normal-weight children: some methodological issues. Am J Epidemiol (2008) 167:653-66. doi:10.1093/aje/kwm348

18. Flynn JT, Kaelber DC, Baker-Smith CM, Blowey D, Carroll AE, Daniels SR, et al. Clinical practice guideline for screening and management of high blood pressure in children and adolescents. Pediatrics (2017) 140(3). doi:10.1542/peds.2017-1904

19. Ouchi N, Parker JL, Lugus JJ, Walsh K. Adipokines in inflammation and metabolic disease. Nat Rev Immunol (2011) 11:85-97. doi:10.1038/nri2921

20. do Carmo JM, da Silva AA, Cai Z, Lin S, Dubinion JH, Hall JE. Control of blood pressure, appetite, and glucose by leptin in mice lacking leptin receptors in proopiomelanocortin neurons. Hypertension (2011) 57:918-26. doi:10.1161/ HYPERTENSIONAHA.110.161349

21. Tallam LS, da Silva AA, Hall JE. Melanocortin-4 receptor mediates chronic cardiovascular and metabolic actions of leptin. Hypertension (2006) 48:58-64. doi:10.1161/01.HYP.0000227966.36744.d9

22. Carlyle M, Jones OB, Kuo JJ, Hall JE. Chronic cardiovascular and renal actions of leptin: role of adrenergic activity. Hypertension (2002) 39:496-501. doi:10.1161/hy0202.104398

23. Kalil GZ, Haynes WG. Sympathetic nervous system in obesity-related hypertension: mechanisms and clinical implications. Hypertens Res (2012) 35:4-16. doi:10.1038/hr.2011.173

24. Vecchiola A, Lagos CF, Carvajal CA, Baudrand R, Fardella CE. Aldosterone production and signaling dysregulation in obesity. Curr Hypertens Rep (2016) 18:20. doi:10.1007/s11906-016-0626-9

25. Kishi T, Hirooka Y. Sympathoexcitation associated with renin-angiotensin system in metabolic syndrome. Int J Hypertens (2013) 2013:406897. doi:10.1155/ 2013/406897

26. Nickenig G, Jung O, Strehlow K, Zolk O, Linz W, Schölkens BA, et al. Hypercholesterolemia is associated with enhanced angiotensin AT1receptor expression. Am J Physiol (1997) 272:H2701-7.

27. Strehlow K, Wassmann S, Bohm M, Nickenig G. Angiotensin AT1 receptor over-expression in hypercholesterolaemia. Ann Med (2000) 32:386-9. doi:10.3109/07853890008995944

28. Millar PJ, Floras JS. Statins and the autonomic nervous system. Clin Sci (Lond) (2014) 126:401-15. doi:10.1042/CS20130332
29. Lambert EA, Chatzivlastou K, Schlaich M, Lambert G, Head GA. Morning surge in blood pressure is associated with reactivity of the sympathetic nervous system. Am J Hypertens (2014) 27:783-92. doi:10.1093/ajh/ hpt 273

30. Dorresteijn JA, Visseren FL, Spiering W. Mechanisms linking obesity to hypertension. Obes Rev (2012) 13:17-26. doi:10.1111/j.1467-789X.2011.00914.x

31. Engeli S, Böhnke J, Gorzelniak K, Janke J, Schling P, Bader M, et al. Weight loss and the renin-angiotensin-aldosterone system. Hypertension (2005) 45:356-62. doi:10.1161/01.HYP.0000154361.47683.d3

32. Kassab S, Kato T, Wilkins FC, Chen R, Hall JE, Granger JP. Renal denervation attenuates the sodium retention and hypertension associated with obesity. Hypertension (1995) 25:893-7. doi:10.1161/01.HYP.25.4.893

33. Jones PP, Davy KP, Alexander S, Seals DR. Age-related increase in muscle sympathetic nerve activity is associated with abdominal adiposity. Am J Physiol (1997) 272:E976-80.

34. Sorof JM, Poffenbarger T, Franco K, Bernard L, Portman RJ. Isolated systolic hypertension, obesity, and hyperkinetic hemodynamic states in children. J Pediatr (2002) 140:660-6. doi:10.1067/mpd.2002.125228

35. Spear BA, Barlow SE, Ervin C, Ludwig DS, Saelens BE, Schetzina KE, et al. Recommendations for treatment of child and adolescent overweight and obesity. Pediatrics (2007) 120(Suppl 4):S254-88. doi:10.1542/peds.2007-2329F

36. Rocchini AP, Katch V, Anderson J, Hinderliter J, Becque D, Martin M, et al. Blood pressure in obese adolescents: effect of weight loss. Pediatrics (1988) 82:16-23.

37. Reinehr T, Schaefer A, Winkel K, Finne E, Toschke AM, Kolip P. An effective lifestyle intervention in overweight children: findings from a randomized controlled trial on "Obeldicks light". Clin Nutr (2010) 29:331-6. doi:10.1016/j. clnu.2009.12.010

38. Reinehr T, de Sousa G, Toschke AM, Andler W. Long-term follow-up of cardiovascular disease risk factors in children after an obesity intervention. Am J Clin Nutr (2006) 84:490-6.

39. Vollmer WM, Sacks FM, Ard J, Appel LJ, Bray GA, Simons-Morton DG, et al. Effects of diet and sodium intake on blood pressure: subgroup analysis of the DASH-sodium trial. Ann Intern Med (2001) 135:1019-28. doi:10.7326/0003-4819-135-12-200112180-00005

40. Couch SC, Saelens BE, Levin L, Dart K, Falciglia G, Daniels SR. The efficacy of a clinic-based behavioral nutrition intervention emphasizing a DASHtype diet for adolescents with elevated blood pressure. JPediatr (2008) 152:494-501. doi:10.1016/j.jpeds.2007.09.022

41. Ebbeling CB, Feldman HA, Chomitz VR, Antonelli TA, Gortmaker SL, Osganian SK, et al. A randomized trial of sugar-sweetened beverages and adolescent body weight. N Engl J Med (2012) 367:1407-16. doi:10.1056/ NEJMoa1203388

42. de Ruyter JC, Olthof MR, Seidell JC, Katan MB. A trial of sugar-free or sugar-sweetened beverages and body weight in children. $N$ Engl J Med (2012) 367:1397-406. doi:10.1056/NEJMoa1203034

43. Chen L, Caballero B, Mitchell DC, Loria C, Lin PH, Champagne CM, et al. Reducing consumption of sugar-sweetened beverages is associated with reduced blood pressure: a prospective study among United States adults. Circulation (2010) 121:2398-406. doi:10.1161/CIRCULATIONAHA. 109.911164

44. Dietary Guidelines for Americans 2015-2020. (2015). Available from: http:// health.gov/dietaryguidelines/2015/guidelines/

45. Yang Q, Zhang Z, Kuklina EV, Fang J, Ayala C, Hong Y, et al. Sodium intake and blood pressure among US children and adolescents. Pediatrics (2012) 130:611-9. doi:10.1542/peds.2011-3870

46. Sharma AM, Pischon T, Engeli S, Scholze J. Choice of drug treatment for obesity-related hypertension: where is the evidence? J Hypertens (2001) 19:667-74. doi:10.1097/00004872-200104000-00001

47. Dahlöf B, Sever PS, Poulter NR, Wedel H, Beevers DG, Caulfield M, et al. Prevention of cardiovascular events with an antihypertensive regimen of amlodipine adding perindopril as required versus atenolol adding bendroflumethiazide as required, in the Anglo-Scandinavian Cardiac Outcomes Trial-Blood Pressure Lowering Arm (ASCOT-BPLA): a multicentre randomised controlled trial. Lancet (2005) 366:895-906. doi:10.1016/ S0140-6736(05)67185-1

48. Ruwald AC, Westergaard B, Sehestedt T, Kjeldsen SE, Lindholm LH, Wachtell $\mathrm{K}$, et al. Losartan versus atenolol-based antihypertensive treatment reduces cardiovascular events especially well in elderly patients: the 
Losartan Intervention for Endpoint reduction in hypertension (LIFE) study. J Hypertens (2012) 30:1252-9. doi:10.1097/HJH.0b013e328352f7f6

Conflict of Interest Statement: The author declares that the research was conducted in the absence of any commercial or financial relationships that could be construed as a potential conflict of interest.
Copyright $\odot 2017$ Brady. This is an open-access article distributed under the terms of the Creative Commons Attribution License (CC BY). The use, distribution or reproduction in other forums is permitted, provided the original author(s) or licensor are credited and that the original publication in this journal is cited, in accordance with accepted academic practice. No use, distribution or reproduction is permitted which does not comply with these terms. 